\title{
FATORES ENVOLVIDOS NA ADESÃO AO TRATAMENTO ANTIRETROVIRAL UTILIZADOS PELOS PACIENTES ATENDIDOS PELO SERVIÇO DE ATENDIMENTO ESPECIALIZADO DE DOURADOS
}

\section{FACTORS INVOLVED IN ADHERENCE TO ANTIRETROVIRAL TREATMENT USED BY PATIENTS SERVED BY THE GOLDEN SPECIALIZED CARE SERVICE}

\author{
Adriana Mary Mestriner Felipe de Melo; Izabeli Martins dos Santos²; Gláucia \\ Eberhardt ${ }^{3}$; Eduardo Henrique Loreti ${ }^{4}$
}

1 - Doutora em Ciências da Saúde (UnB), Mestre em Microbiologia (UEL), docente da Unigran.

2 - Discente do curso de Farmácia.

3 - Farmacêutica, Mestre em ciências da Saúde (UFGD), Farmacêutica da Prefeitura Municipal de Dourados. 4 - Fisioterapeuta, Mestre, docente na Unigran.

\section{RESUMO:}

O tratamento antirretroviral (TARV) tem sido instituído ao longo dos últimos anos visando reduzir a replicação viral de tal forma que aumentasse a sobrevida do paciente infectado. Nos últimos anos, o TARV tem sido também aplicado como estratégia de redução da carga viral desde o diagnóstico visando diminuir as transmissões pela redução da carga viral no paciente infectado. Considerando que nem todos os pacientes entendem a importância dessa etapa e o reflexo da descontinuidade dentro do processo de evolução da infecção pelo HIV em seu organismo, a presente pesquisa teve o objetivo de avaliar a adesão ao tratamento de pacientes atendidos pelo serviço de assistência especializado (SAE). A pesquisa trata-se de um estudo de campo descritivo, realizada com pacientes atendidos pelo atendimento especializado de Dourados. Os dados obtidos dos pacientes atendidos na cidade de Dourados mostram que a adesão ao tratamento antirretroviral foi satisfatória e pode estar relacionado como alto índice de escolaridade, que garante a pessoa uma boa compreensão. Além dos esquemas mais utilizados serem aqueles indicados pelo protocolo, com menores doses diárias, baixos efeitos colaterais e serem disponibilizados na rede pública, porém, as pessoas mais jovens são as que mais possuem meios de informações simples, mas são o perfil que mais cresce.

Palavras-chave: HIV, Tratamento antirretroviral, Esquemas terapêuticos

\section{ABSTRACT:}

Antiretroviral treatment (ART) has been instituted over the past few years to reduce viral replication in such a way as to increase the survival of the infected patient. In recent years, HAART has also been used as a viral load reduction strategy since the diagnosis qualified as transmissions by reducing viral load in the infected patient. The service that not all patients understand the importance of this stage and the reflection of the discontinuity within the evolution process of the HIV infection in their organism, a present research had the objective to evaluate the adherence to the treatment of patients attended by the specialized assistance service (SAE) The research is a descriptive field study, carried out with patients attended by the specialized service in Dourados. The data obtained from patients seen in the city of Dourados show that adherence to antiretroviral treatment was satisfactory and may be related to a high level of education, which guarantees a person a good 
understanding. In addition to the most used schemes being those indicated by the protocol, with lower lower doses, low side effects and being made available on the public network, however, younger people are the ones who have the most simple means of information, but they are the profile that grows the most.

Keywords: HIV, Antiretroviral treatment, Therapeutic schemes

\section{INTRODUÇÃO}

Os primeiros casos de AIDS (Síndrome Da Imunodeficiência Adquirida) foram verificados na década de oitenta. Apesar dos avanços tecnológicos e de mais de 20 anos desde a descoberta do vírus HIV (vírus da imunodeficiência humana) ainda existe um grande desafio na compreensão dos aspectos desta doença (WHO, 2007).

De acordo com Organização Mundial da Saúde (2007), a prevalência e incidência da infecção por HIV predomina em países em desenvolvimento. No entanto, após a descoberta dos medicamentos antirretrovirais as taxas de morbidade e mortalidade sofreram uma drástica diminuição, melhorando a qualidade e expectativa de vida das pessoas que vivem e convivem com o HIV (PVHIV) (BARLETT, 2002). Contudo, há uma grande preocupação em relação ao acesso universal destas medicações, já que os recursos oferecidos são limitados e os números de casos permanecem em crescimento tornando esta uma doença de caráter epidêmico (BRASIL, 2005).

A assistência prestada aos pacientes que vivem e convivem com HIV é realizada pelos Serviços de Assistência Especializada (SAE), se distinguindo por sua administração, podendo ser municipal, estadual ou federal. Paralelamente a este serviço, os Centros de Testagem e Aconselhamento (CTA) realizam a identificação de casos novos de infecção por HIV, visando o diagnóstico e a promoção da saúde através de ações voltadas para a prevenção desta e outras infecções sexualmente transmissíveis (IST) (BRASIL, 2014).

Para o atendimento frente esta doença o Ministério da Saúde elaborou o Protocolo Clínico e as Diretrizes Terapêuticas (PCDT) em IST/HIVIAIDS. Para tal, o cuidado com o paciente é um ponto fundamental, sendo a dispensa dos antirretrovirais a ligação entre o sistema de saúde e o usuário (BRASIL, 2010). Neste contexto, os profissionais de saúde têm papel fundamental no monitoramento dos índices de baixa adesão aos tratamentos antirretrovirais, tendo em vista a diminuição da eficácia terapêutica que conduz o paciente a uma piora clínica, além da disseminação de cepas resistentes que culminam na limitação das opções medicamentosas (CARACIOLO et al., 2007).

A adesão ao tratamento pode ser entendida como um processo em que o paciente não segue apenas a orientação, mas também aceita a prescrição médica recomendada 
(CARDOSO; ARRUDA. 2004). Entre alguns termos utilizados por autores para descrever adesão, se destaca o termo persistência, que está relacionado com o tempo que o paciente continua seu tratamento (CRAMER et al., 2008, RAEBEL et al., 2013). Podendo ser analisada também como as retiradas contínuas, ou seja, o tempo entre o início e a descontinuação da terapia, dessa forma, pode se concluir que o indivíduo é persistente quando retira suas medicações em seu tempo determinado (CRAMER et al., 2008; PETERSON et al., 2007; RAEBEL et al., 2013; SATTLER, LEE e PERRI, 2013).

Diversos fatores podem influenciar na efetividade do tratamento antirretroviral. Alguns, como o perfil sociocultural e econômico, a aceitação do diagnóstico e a atenção com a adesão são importantes para determinar medidas que facilitam ou dificultam a implementação de ações estratégicas para auxiliar a promoção de saúde e uma melhor qualidade de vida (Mills et al.,2006).

A utilização de esquemas terapêuticos em doses fixas combinadas, com um número reduzido de dosagens diárias e de baixos efeitos colaterais facilita a continuidade do tratamento antirretroviral (TARV). A adesão é um parâmetro essencial a ser observado considerando que, por ser uma doença crônica, as pessoas que vivem e convivem com o HIV necessitam utilizar dos medicamentos por toda vida (CHEN, 2007). A efetividade medicamentosa dos antirretrovirais é diretamente observada em PVHIV que mantêm uma carga viral do HIV reduzida, no entanto a suspenção ou a falha do tratamento compromete esse controle e como consequência pode haver um aumento nesta carga viral e, respectivamente, uma diminuição de células LT-CD4, prejudicando assim a saúde do indivíduo (CECCATO, 2004). Apesar de ser o padrão ouro para a monitoração de efetividade medicamentosa, a determinação da carga viral para HIV possui limitações, sendo assim, é importante a utilização de mais de um método para avaliação (SCHECTER, 2008).

Cuidados prestados às PVHIV perpassa diversas dimensões a fim de garantir um serviço de saúde de qualidade, sejam elas técnicas, de disponibilidade de recursos, de gerenciamento, e primordialmente, através das relações estabelecidas entre usuários e profissionais. No caso das unidades dispensadoras de medicamentos (UDM), o farmacêutico possui papel de destaque no fornecimento de informações determinantes, na supervisão e orientação sobre a adequações dos esquemas ARV's, doses, posologias e interações medicamentosas, na participação de grupos de adesão e controle de faltosos, na interação com a equipe multidisciplinar, no manejo dos aspectos clínicos e na notificação de efeitos adversos (SAUDE, 2010).De acordo com Rossi et al. (2012) entender as 
características individuais e contexto do paciente com o vírus do HIV, bem como os fatores que podem intervir no processo de adesão ao tratamento por parte do paciente são de grande importância para o acompanhamento, monitoração e avaliação dos serviços de saúde e seus usuários.

Desta forma, esta pesquisa teve como objetivo realizar um levantamento sobre os medicamentos utilizados pelos pacientes atendidos pelo Serviço de Atendimento Especializado de Dourados, bem como avaliar e determinar os fatores envolvidos na adesão ao tratamento.

\section{MATERIAL E MÉTODOS}

A presente pesquisa trata-se de um estudo descritivo de campo, já que, coletou dados dos serviços e posteriormente os analisou e interpretou.

A amostra estudada foi retirada a partir da coleta de informações em prontuários de pacientes que iniciaram tratamento entre os anos de 2018 a 2019 no Serviço de Atendimento Especializado de Dourados, seguindo os parâmetros para estabelecer um padrão e determinar como o paciente adere ao tratamento. O local escolhido foi por ser o único autorizado a dispensar medicamentos antirretrovirais a pacientes da cidade e região.

Tratando-se de uma pesquisa que envolve seres humanos, houve aprovação do Comitê de Ética em Pesquisa (CEP) do Centro Universitário da Grande Dourados (UNIGRAN), e da Prefeitura de Dourados (Parecer 3.914.649). As identidades dos participantes foram mantidas em sigilo.

Foram excluídos os prontuários que pertenciam a menores de dezoito anos, aqueles com etnia indígena. Em contrapartida, foram inseridos os prontuários de pessoas que tiveram início do tratamento entre 2018 e 2019, sem distinção de gênero, após cálculo amostral para população finita, e dessa forma obteve-se um total de 183 pacientes, sendo sorteados números aleatórios que correspondiam aos participantes.

Após a coleta dos dados (sexo, idade, escolaridade, situação conjugal, orientação sexual, tempo de diagnóstico e início de medicação, acompanhamento médico, carga viral e LT-CD4 pré e pós medicação e esquema terapêutico inicial e atual).

Lançou-se mão dos cálculos de porcentagem e interpretação de gráficos para demonstrar o número e o perfil de pacientes aderentes ao tratamento e os medicamentos utilizados, além do cálculo estatístico do valor-p, que determina quais amostras possuem valores significantes para a análise, desta forma, foi utilizada um valor de corte de $5 \%$, sendo assim qualquer valor diferente será rejeitado e considerado uma diferença estatística significativa. 


\section{RESULTADOS E DISCUSSÃO}

Dentre os itens observados, o primeiro aspecto que foi observado para determinar a adesão ao tratamento foram os exames de carga viral e LT-CD4 do paciente, comparando com os resultados de antes e depois do início de medicação observando se houve ou não uma melhora. Em seguida considerou-se as retiradas de medicação, sendo esta análise feita de acordo com o que foi registrado, sendo examinada mensalmente, determinando a porcentagem de tomadas de medicamento. Para determinar a aderência no tratamento, foi separado aqueles que possuíam um alto valor de tomadas, maior que $95 \%$, médio valor, menor ou igual a $95 \%$ até $85 \%$, e com baixo valor, menor que $85 \%$.

Por meio dos dados coletados, percebeu-se que a maioria dos pacientes que iniciaram o tratamento entre os anos de 2018 a 2019 foi do sexo masculino, com um total de $135(73,8 \%)$ pacientes, diferente do sexo feminino, que obteve um total de $48(26,2 \%)$ pacientes. Em relação a faixa etária, a maioria pertence ao grupo de 18 a 29 anos $(36,1 \%)$, em seguida os que possui idade entre 30 a 39 anos (28,9\%). Nessa primeira análise é possível identificar que o público jovem e masculino são os de maior número, assim como os dados publicados no boletim epidemiológico HIV/Aids do ano de 2018, no qual, nesse mesmo ano no Brasil, 12.505 homens, sendo a maioria com idade entre 25 a 34 anos foram notificados com HIV, em contra partida, houve apenas 4.737 de mulheres, sendo a faixa etária de 30 a 39 anos, mantendo a idade comum aos pacientes em estudo (BRASIL, 2018).

Diferente do perfil mostrado no Boletim, no qual mostra a maioria sendo homossexual, $5.708(52.5 \%)$, houve $82(44,8 \%)$ pacientes que se autodenominaram como heterossexual, e apenas 47 (25,7\%) homossexual/gay/lésbica (BRASIL, 2018).

Em seguida foi realizada a coleta de escolaridade e situação conjugal, sendo possível determinar que $111(60,7 \%)$ destes estudaram até os 12 anos ou mais e 125 $(68,3 \%)$ são solteiros. Comparando o intervalo de tempo entre o diagnóstico e o início da TARV foi possível observar que $127(69,4)$ dos participantes iniciaram em até 2 meses do diagnóstico, sendo que, 159 (86,9) são atendidos pela rede pública (Tabela 1). Apesar do conhecimento e a informatização a respeito do acesso ao diagnóstico e tratamento, a maioria dos pacientes que procuram o serviço de testagem e tem o diagnóstico positivo, iniciam com uma imunossupressão avançada (COSTA et al.,2018). 
Tabela 1 - Distribuição dos dados sociodemográficos dos participantes que constituem a população deste estudo.

\begin{tabular}{|c|c|}
\hline Variáveis sociodemográficas & $n(\%)$ \\
\hline \multicolumn{2}{|l|}{ Sexo } \\
\hline Masculino & $135(73,8)$ \\
\hline Feminino & $48(26,2)$ \\
\hline \multicolumn{2}{|l|}{ Idade } \\
\hline 18 a 29 anos & $66(36,1)$ \\
\hline 30 a 39 anos & $53(28,9)$ \\
\hline 40 a 49 anos & $31(16,9)$ \\
\hline 50 a 59 anos & $23(12,6)$ \\
\hline$\geq 60$ anos & $10(5,5)$ \\
\hline \multicolumn{2}{|l|}{ Escolaridade } \\
\hline Nenhuma & $2(1,1)$ \\
\hline De 1 a 3 anos & $2(1,1)$ \\
\hline De 4 a 7 anos & $33(18,0)$ \\
\hline De 8 a 11 anos & $25(13,7)$ \\
\hline$\geq 12$ anos & $111(60,7)$ \\
\hline Não informado & $10(5,5)$ \\
\hline \multicolumn{2}{|l|}{ Situação conjugal } \\
\hline Solteiro & $125(68,3)$ \\
\hline Casado & $31(16,9)$ \\
\hline União estável & $5(2,7)$ \\
\hline Separado/divorciado & $12(6,6)$ \\
\hline Viúvo & $5(2,7)$ \\
\hline Não informado & $5(2,7)$ \\
\hline \multicolumn{2}{|l|}{ Orientação Sexual } \\
\hline Heterossexual & $82(44,8)$ \\
\hline Homossexual/Gay/Lésbica & $47(25,7)$ \\
\hline Bissexual & $12(6,6)$ \\
\hline Não informado & $42(22,9)$ \\
\hline \multicolumn{2}{|c|}{ Intervalo de tempo entre diagnóstico e início de } \\
\hline \multicolumn{2}{|c|}{ TARV } \\
\hline Até 2 meses & $127(69,4)$ \\
\hline$\geq 2$ meses & $56(30,6)$ \\
\hline \multicolumn{2}{|l|}{ Acompanhamento médico } \\
\hline Público & $159(86,9)$ \\
\hline Privado & $24(13,1)$ \\
\hline
\end{tabular}

A carga viral plasmática reflete a dinâmica desse vírus nos indivíduos infectados, quantificando as partículas que estão sendo produzidas e lançadas na circulação sanguínea, sendo muito útil para avaliar a progressão da doença, indicar o início de terapia e para determinar a eficácia dos antirretrovirais. Em paralelo com os exames de carga viral é fundamental o acompanhamento das células LT-CD4. Isso porque, a quantificação dos linfócitos T CD4+ abaixo de 500 células/ $\mathrm{mm}^{3}$, ou inferiores a $24 \%$, são considerados alterados. Os pacientes com contagem de células abaixo de 200 células $/ \mathrm{mm}^{3}$ ficam suscetíveis a doenças oportunistas (BRASIL, 2013). 
Primeiro foi avaliado a carga viral antes do início da medicação antirretroviral, onde, a maioria, 66 (36,1\%), tiveram carga maior que 30.000 , e $34(18,6 \%)$ não realizaram ou não informaram exames antes de iniciarem o tratamento. Juntamente avaliou-se o primeiro exame realizado após o início dos medicamentos, onde apresentou os seguintes resultados, $138(75,4 \%)$ obtiveram carga menor que 50 cópias e $14(7,7 \%)$ dessas pessoas ainda não realizaram esse exame.

Antes do medicamento observou que 47 (25,7\%) dos participantes tiveram resultado abaixo de 200 células/mm3, após começarem com a medicação esse número mudou, sendo que, $66(36,1 \%)$ tenham agora um resultado de 500 células/mm3, porém, o número de exames não realizados foram de 37 (20,2\%) pré-TARV e de 16 (8,7\%) pósTARV (Tabela 2). Em 2013 o uso da TARV independentemente da contagem de LT-CD4+ foi adotado, o que garante uma redução de $50 \%$ na incidência de eventos sérios relacionados à aids, como morte e doenças oportunistas. Pacientes que iniciam a TARV com menor intervalo após o diagnóstico tem maior chance de atingir a supressão viral em 12 meses (COSTA et al.,2018).

Tabela 2. Caracterização dos participantes do estudo em função das variáveis clínicas.

\begin{tabular}{lc}
\hline Variáveis clínicas & $\mathbf{n}(\%)$ \\
\hline CV pré-Tarv (cópias/mL) & $3(1,6)$ \\
$<50$ & $27(14,8)$ \\
50 a 500 & $25(13,7)$ \\
501 a 10.000 & $28(15,3)$ \\
10.001 a 30.000 & $66(36,1)$ \\
$>$ > 30.000 & $34(18,6)$ \\
Não informado & \\
CV pós-Tarv (cópias/mL) & $138(75,4)$ \\
$<50$ & $23(12,6)$ \\
50 a 500 & $3(1,6)$ \\
501 a 10.000 & $1(0,5)$ \\
10.001 a 30.000 & $4(2,2)$ \\
$>30.000$ & $14(7,7)$ \\
Não realizado & \\
LT-CD4 pré-TARV & $47(25,7)$ \\
< 200 & $38(20,8)$ \\
200 a 350 & $23(12,6)$ \\
351 a 500 & $38(20,8)$ \\
> 500 & $37(20,2)$ \\
Não informado & \\
LT-CD4 pós-TARV & $34(18,6)$ \\
< 200 & $32(17,5)$ \\
200 a 350 & $35(19,1)$ \\
351 a 500 & $66(36,1)$ \\
> 500 & $16(8,7)$ \\
Não realizado &
\end{tabular}


Contudo, foram classificados os dados relativos à adesão ao tratamento com base na contagem de retiradas mensais do medicamento, sendo divididos em baixa, com 108 $(59,0 \%)$ pacientes, média, $36(19,7 \%)$ e alta adesão com $39(21,3 \%)$.

Tabela 3. Classificação dos dados relativos à adesão ao tratamento com antirretrovirais.

\begin{tabular}{lc}
\hline Níveis de adesão & $\mathbf{n ~ ( \% )}$ \\
\hline Baixo $(\leq 85 \%)$ & $108(59,0)$ \\
Médio $(>85$ a $95 \%)$ & $36(19,7)$ \\
Alto $(>95 \%)$ & $39(21,3)$ \\
\hline
\end{tabular}

Assim, ao relacionar os dados sociodemográficos com os determinados níveis, pode-se perceber que a maioria dos pacientes do sexo masculino possui alta adesão, 87 $(64,4 \%)$, da mesma forma que o sexo feminino, 21 (43,8\%), entretanto, 19,3\% de homens e $20,8 \%$ de mulheres tem média adesão. O número de pacientes com baixa adesão em homens não é significante, apenas, 16,3\%, mas e mulheres a porcentagem esta alta, $35,4 \%$.

O perfil de pacientes que tiveram uma adesão ao tratamento forma pacientes relativamente jovens, entre 18 a 29 anos, $(41 ; 62,1 \%)$, com mais de 12 anos de escolaridade $(74 ; 66,7 \%)$, solteiros $(75 ; 60,0 \%)$, heterossexual $(49 ; 59,8 \%)$, que iniciaram tratamento até 2 meses (76; 60,0\%) e fazem acompanhamento público (92; 57,9\%).

Já aqueles que foram enquadrados com "média adesão" possuem entre 30 a 39 anos $(16 ; 30,2 \%)$, com mesmo tempo de escolaridade total de 12 anos $(37 ; 33,3 \%)$, solteiros, 26 (20,8\%), heterossexual 13 (15,9\%), com intervalo de tempo de diagnóstico de até 2 meses (23;18\%), em acompanhamento médico público (30;18,9\%). Os de baixa adesão, fazem parte do grupo com idade entre 18 a 29 anos (13; 19,7\%), com escolaridade de 4 a 7 anos (8; 24,2\%), solteiros (24; 19,2\%), heterossexual (20; 24,4\%), que iniciaram tratamento até 2 meses, 28 (22,0\%) e fazem acompanhamento público (37, 23,2\%) (Tabela 4).

Porém o teste de valor-p (probabilidade de significância) mostra quais os dados são realmente relevantes, sendo que a valor deve ser menor que $5 \%$. Dessa forma, os pacientes do sexo masculino, idade entre 18 a 29 anos, com escolaridade maior ou igual a 12 anos, solteiros, heterossexual, que iniciaram tratamento em 2 meses ou mais e são 
acompanhados na rede pública são os que possuem uma alta adesão, com resultados significantes para este estudo.

De acordo com o protocolo de manejo da infecção pelo HIV em adultos estabelecido pelo Ministério da Saúde, o esquema inicial preferencial deve ser uma associação de dois inibidores de transcriptase reversa a um inibidor de integrase, sendo eles, lamivudina (3TC), tenofovir (TDF) e dolutegravir (DTG). Nos participantes tivemos $88,5 \%$ que iniciaram com esse esquema, e 89,6\% usam atualmente, porém, para pessoas coinfectados pela Tuberculose há um esquema alternativo, com lamivudina (3TC), tenofovir (TDF) e efavirenz (EFV), em uso desse esquema iniciaram apenas 5,5\%, e atualmente apenas 4,9\%. Contudo para pacientes que além da Tuberculose possuem critérios de gravidade como, LT-CD4 menor que 100 células $/ \mathrm{mm} 3$, outra infecção oportunista ou internação hospitalar é necessário iniciar com lamivudina (3TC), tenofovir (TDF) e raltegravir (RAL), dessa mesma forma em situações nas quais DTG não é recomendado, como gestantes, uso concomitante de rifampicina ou anticonvulsivantes sem possibilidade de troca, entre os pacientes, 3,8\% usaram quando iniciaram, e 2,7\% usam atualmente.

Em situações especiais de intolerância ou contraindicação devem ter seus esquemas iniciais adequados para esquemas alternativos, como, o abacavir (ABC), lamivudina (3TC) e dolutegravir (DTG), são recomendados para aqueles com contraindicação aos esquemas com TDF/3TC. Apenas 0,5\% iniciaram e ainda continuam com essa medicação. A zidovudina (AZT) com lamivudina (3TC) tem eficácia e segurança equivalentes a outras combinações, mas devem ser evitadas por casos de anemia e neutrófilos abaixo de 1.000 céls $/ \mathrm{mm} 3$, somente $0,5 \%$ iniciaram com esse esquema e agora $1,1 \%$ estão em uso. 
Tabela 4. Distribuição dos dados sociodemográficos conforme o nível de adesão à terapia antirretroviral.

\begin{tabular}{|c|c|c|c|c|c|}
\hline $\begin{array}{l}\text { Variáveis } \\
\text { sociodemográficas }\end{array}$ & $\begin{array}{c}\text { Alta } \\
\text { adesão } \\
>95 \% \\
\mathrm{n}(\%)\end{array}$ & $\begin{array}{c}\text { Média } \\
\text { adesão } \\
>85 \text { a } 95 \% \\
\text { n (\%) } \\
\end{array}$ & $\begin{array}{c}\text { Baixa } \\
\text { adesão } \\
\leq 85 \% \\
\mathrm{n}(\%) \\
\end{array}$ & Total $n(\%)$ & $\begin{array}{c}\text { Valor de } \\
\mathbf{p}\end{array}$ \\
\hline \multicolumn{6}{|l|}{ Sexo } \\
\hline Masculino & $87(64,4)$ & $26(19,3)$ & $22(16,3)$ & $135(100)$ & $<0,05$ \\
\hline Feminino & $\begin{array}{c}21 \\
(43,8)\end{array}$ & $10(20,8)$ & $17(35,4)$ & $48(100)$ & 0,12 \\
\hline \multicolumn{6}{|l|}{ Idade } \\
\hline 18 a 29 anos & $41(62,1)$ & $12(18,2)$ & $13(19,7)$ & $66(100)$ & $<0,01$ \\
\hline 30 a 39 anos & $25(47,2)$ & $16(30,2)$ & $12(22,6)$ & $53(100)$ & 0,19 \\
\hline 40 a 49 anos & $20(64,5)$ & $5(16,1)$ & $6(19,4)$ & $31(100)$ & $<0,01$ \\
\hline 50 a 59 anos & $17(73,9)$ & $1(4,3)$ & $5(21,7)$ & $23(100)$ & $<0,05$ \\
\hline$\geq 60$ anos & $5(50,0)$ & $2(20,0)$ & $3(30,0)$ & $10(100)$ & 0,16 \\
\hline \multicolumn{6}{|l|}{ Escolaridade } \\
\hline Nenhuma & $0(0)$ & $0(0)$ & $2(100)$ & $2(100)$ & 0,46 \\
\hline De 1 a 3 anos & $0(0)$ & $1(50,0)$ & $1(50,0)$ & $2(100)$ & 0,65 \\
\hline De 4 a 7 anos & $18(54,5)$ & $7(21,2)$ & $8(24,2)$ & $33(100)$ & 0,057 \\
\hline De 8 a 11 anos & $12(48,0)$ & $6(24,0)$ & $7(28,0)$ & $25(100)$ & $<0,05$ \\
\hline$\geq 12$ anos & $74(66,7)$ & $37(33,3)$ & $0(0)$ & $111(100)$ & $<0,05$ \\
\hline Não informado & $4(40,0)$ & $3(30,0)$ & $3(30,0)$ & $10(100)$ & 0,99 \\
\hline \multicolumn{6}{|l|}{ Situação conjugal } \\
\hline Solteiro & $75(60,0)$ & $26(20,8)$ & $24(19,2)$ & $125(100)$ & $<0,05$ \\
\hline Casado & $16(51,6)$ & $4(12,9)$ & $11(35,5)$ & $31(100)$ & $0,05^{*}$ \\
\hline União estável & $2(40)$ & $2(40)$ & $1(20)$ & $5(100)$ & 0,53 \\
\hline Separado/divorciado & $9(75,0)$ & $1(8,3)$ & $2(16,7)$ & $12(100)$ & $<0,05$ \\
\hline Viúvo & $3(60,0)$ & $1(20,0)$ & $1(20,0)$ & $5(100)$ & 0,38 \\
\hline Não informado & $3(60,0)$ & $2(40,0)$ & $0(0)$ & $5(100)$ & 0,07 \\
\hline \multicolumn{6}{|l|}{ Orientação Sexual } \\
\hline Heterossexual & $49(59,8)$ & $13(15,9)$ & $20(24,4)$ & $82(100)$ & $<0,05^{*}$ \\
\hline Homossexual/Gay/Lésbica & $23(49,0)$ & $12(25,5)$ & $12(25,5)$ & $47(100)$ & 0,07 \\
\hline Bissexual & $10(83,0)$ & $0(0)$ & $2(17,0)$ & $12(100)$ & $<0,01$ \\
\hline Não informado & $26(61,9)$ & $11(26,2)$ & $5(11,9)$ & $42(100)$ & 0,052 \\
\hline \multicolumn{6}{|l|}{$\begin{array}{l}\text { Intervalo de tempo entre } \\
\text { diagnóstico e início de TARV }\end{array}$} \\
\hline Até 2 meses & $76(60,0)$ & $23(18,0)$ & $28(22,0)$ & $127(100)$ & 0,06 \\
\hline$\geq 2$ meses & $32(57,1)$ & $13(23,2)$ & $11(19,6)$ & $56(100)$ & $<0,05$ \\
\hline \multicolumn{6}{|l|}{ Acompanhamento médico } \\
\hline Público & $92(57,9)$ & $30(18,9)$ & $37(23,2)$ & $159(100)$ & $<0,05$ \\
\hline Privado & $16(66,7)$ & $6(25,0)$ & $2(8,3)$ & $24(100)$ & $<0,05^{\#}$ \\
\hline
\end{tabular}

*Alta adesão comparado com média adesão

\#Alta adesão comparado com baixa adesão 
Dessa maneira o estudo mostra como os registros de farmácia são importantes para informar como os pacientes seguem o tratamento. A forma de monitorar a adesão usada é simples e permite usar os dados coletados de forma mensal, em cada visita dos pacientes, tal como é recomendado pela OMS. Os resultados desta análise indicam a situação deste serviço público de referência, mostrando resultados satisfatórios com relação à adesão aos ARV.

Tabela 5. Classificação dos esquemas terapêuticos antirretrovirais inicial e atual.

\begin{tabular}{cccc}
\hline Esquema terapêutico inicial & $\mathbf{n}(\%)$ & Esquema terapêutico atual & $\mathbf{n}(\%)$ \\
\hline 3TC/TDF+DTG & $162(88,5)$ & 3TC/TDF+DTG & $164(89,6)$ \\
3TC/TDF+RAL & $7(3,8)$ & 3TC/TDF+RAL & $5(2,7)$ \\
3TC/TDF/EFZ & $10(5,5)$ & 3TC/TDF/EFZ & $9(4,9)$ \\
3TC/TDF+ATZ+RTV & $2(1,1)$ & 3TC/TDF+ATZ+RTV & $2(1,1)$ \\
3TC/AZT+DTG & $1(0,5)$ & 3TC/AZT+DTG & $2(1,1)$ \\
ABC+DTG+3TC & $1(0,5)$ & ABC+DTG+3TC & $1(0,5)$ \\
\hline
\end{tabular}

\section{CONCLUSÕES}

Os dados obtidos dos pacientes atendidos na cidade de Dourados mostram que a adesão ao tratamento antirretroviral foi satisfatória e pode estar relacionado como alto índice de escolaridade, que garante a pessoa uma boa compreensão. Além dos esquemas mais utilizados serem aqueles indicados pelo protocolo, com menores doses diárias, baixos efeitos colaterais e serem disponibilizados na rede pública, porém, as pessoas mais jovens são as que mais possuem meios de informações simples, mas são o perfil que mais cresce. Portanto é de suma importância a atenção do profissional de saúde com o paciente na implementação de estratégias para que a adesão continue evitando possíveis transmissões. 


\section{REFERÊNCIAS}

BARTLETT, John A. Addressing the challenges of adherence. Journal of acquired immune deficiency syndromes (1999), v. 29, p. S2-10, 2002.

BRASIL. Boletim Epidemiológico de Aids e DST. Brasília (DF): Ministério da Saúde, Secretaria de Vigilância em Saúde; Disponível em http://www.aids.gov.br/ptbr/pub/2018/boletimepidemiologico-de-aids-2018 acesso em 01 de janeiro de 2021.

BRASIL. Departamento de DST/Aids e Hepatites Virais. Portal sobre AIDS, doenças sexualmente transmissíveis e Hepatites Virais. - Brasília, 2014.

BRASIL. Ministério da Saúde, Secretaria de Vigilância em Saúde. Departamento de DST, AIDS e Hepatites Virais. Protocolo de assistência farmacêutica em DST/ HIV/ Aids: recomendações do Grupo de Trabalho de Assistência Farmacêutica. - Brasília, 2010.

BRASIL. Ministério da Saúde. Secretaria de Vigilância em Saúde. Programa Nacional de DST e Aids. O Remédio via Justiça. Secretaria da Vigilância em Saúde, Programa Nacional de DST e Aids. - Brasília, 2005.

CARDOSO G, ARRUDA, A. As representações sociais da soropositividade e sua relação com a observância terapêutica. Ciência \& Saúde Coletiva, v. 10, n. 1, p. 151-162, 2004.

CECCATO, Maria das Graças Braga et al. Compreensão de informações relativas ao tratamento anti-retroviral entre indivíduos infectados pelo HIV. Cadernos de Saúde Pública, v. 20, p. 1388-1397, 2004.

CHEN, Luke F.; HOY, Jennifer; LEWIN, Sharon R. Ten years of highly active antiretroviral therapy for HIV infection. Medical Journal of Australia, v. 186, n. 3, p. 146-151, 2007.

COSTA, J.O., CECCATO, M.G.B., SILVEIRA, M.R., BONOLO, P.F., REIS, E.A., COSTA, Juliana de Oliveira et al. Effectiveness of antiretroviral therapy in the single-tablet regimen era. Revista de saude publica, v. 52, p. 87, 2018.

CRAMER, Joyce A. et al. Medication compliance and persistence: terminology and definitins. Value in health, v. 11, n. 1, p. 44-47, 2008. 
MILLS, Edward J. et al. Adherence to HAART: a systematic review of developed and developing nation patient-reported barriers and facilitators. PLoS Med, v. 3, n. 11, p. e438, 2006.

PETERSON, Andrew M. et al. A checklist for medication compliance and persistence studies using retrospective databases. Value in health, v. 10, n. 1, p. 3-12, 2007.

RAEBEL, Marsha A. et al. Standardizing terminology and definitions of medication adherence and persistence in research employing electronic databases. Medical care, v. 51, n. 80 3, p. S11, 2013.

ROSSI, Silvia Maria Gomes de et al. Impacto da terapia antirretroviral conforme diferentes consensos de tratamento da Aids no Brasil. Revista Panamericana de Salud Pública, v. 32, p. 117-123, 2012.

SATTLER, Elisabeth Lilian Pia; LEE, Jung Sun; PERRI, Matthew. Medication (re) fill adherence measures derived from pharmacy claims data in older Americans: a review of the literature. Drugs \& aging, v. 30, n. 6, p. 383-399, 2013.

SCHECHTER, M., RACHID, M. Manual de HIVIAIDS - 9. Ed. - Editora Revinter. 2008.

WHO. World Health Organization. Aids Epidemicupdate 2007. Geneva; 2007.

Autor para correspondência:

Adriana Mary Mestriner Felipe de Melo

Email: mestriner@unigran.br

Centro Universitário da Grande Dourados (UNIGRAN)

Recebido: 27/02/2021 Aceite: 20/05/2021 